\title{
A review of research on seismic behaviour of irregular building structures since 2002
}

\author{
Mario De Stefano - Barbara Pintucchi
}

Received: 26 July 2006 / Accepted: 27 September 2007 / Published online: 23 November 2007

(C) Springer Science+Business Media B.V. 2007

\begin{abstract}
The paper presents an overview of the progress in research regarding seismic response of plan and vertically irregular building structures. Three areas of research are surveyed. The first is the study of the effects of plan-irregularity by means of single-storey and multi-storey building models. The second area encompasses passive control as a strategy to mitigate torsional effects, by means of base isolation and other types of devices. Lastly, the third area concerns vertically irregular structures and setback buildings. Although fewer papers have been published in this last area with respect to the former ones, this state-of-theart reports extensively on research efforts and progress into the seismic behaviour of irregular buildings in elevation to show the growing interest among specialists in the field.
\end{abstract}

Keywords Torsional response $\cdot$ Irregular structures $\cdot$ Asymmetric structures · One-storey and multi-storey models $\cdot$ Passive control $\cdot$ Setback buildings

\section{Introduction}

Real structures are almost always irregular as perfect regularity is an idealization that very rarely occurs. Structural irregularities may vary dramatically in their nature and, in principle, are very difficult to define. Regarding buildings, for practical purposes, major seismic codes distinguish between irregularity in plan and in elevation, but it must be realized that quite often structural irregularity is the result of a combination of both types. The tendency to separate irregularity in plan and in elevation also characterizes the scientific literature and, therefore, this state-of-the-art review will follow such distinction.

Starting with plan irregularity, assessments of structural performance during past earthquakes demonstrates that this type of irregularity, which is due to asymmetric distributions of mass, stiffness and strength, is one of the most frequent sources of severe damage, since it results in floor rotations (torsional response) in addition to floor translations. In past years, large

M. De Stefano · B. Pintucchi $(\varangle)$

Dipartimento di Costruzioni, Università di Firenze, Piazza Brunelleschi 6, 50121 Florence, Italy

e-mail: barbara.pintucchi@unifi.it 
research efforts were devoted to the study of the seismic response of asymmetric structures and improving torsional provisions of seismic codes. A recent review of research development up to 2001 can be found in Rutenberg (2002).

Most of the aforementioned studies were conducted using simple single-storey asymmetric models, which still remain very popular. However, published research on more realistic multistorey buildings is growing as well.

A large number of papers published in the last 3 years deal with passive control, which appears to be a suitable alternative to traditional design in order to mitigate torsional effects. Such studies have been devoted mainly to base isolation and viscous and visco-elastic damping devices, though friction dampers and other devices are also considered.

A relative paucity of experimental studies still characterizes the scenario of research activities in the field of irregular structures.

Concerning vertically irregular structures and setback buildings, following the relative lack of papers published in the years immediately prior to 2002, in recent years, investigations on seismic behavior of irregular buildings in elevation have intensified, thanks in part to the greater availability of efficient nonlinear dynamic 3D computer codes.

\section{One storey plan-asymmetric building structures}

In the past, effects of torsional coupling in asymmetric building structures were widely investigated by means of simple one-storey models. Such models were considered suitable to clarify the influence of key structural parameters and develop design measures applicable to some classes of multi-storey asymmetric buildings as well. In recent years, multi-storey building models have been used to study more realistically inelastic earthquake response of asymmetric buildings. Nevertheless, due to their complexity, such models are applicable to the study of few cases of real buildings. For this reason, single-storey models still attract many researchers, as they remain adequate to obtain general information on torsional behavior of asymmetric buildings, particularly from a qualitative point of view.

In recent years, papers on single-storey models have been focusing on the inelastic behavior of resisting elements, the effects of bi-directional excitation, and other aspects neglected in previous research. Investigations have also been conducted with reference to bi-asymmetric models, besides to the mono-symmetric ones used so far.

In particular, inelastic behavior is of great interest, since the ability of structures to withstand strong earthquakes depends upon their ductility and capacity for energy dissipation. In spite of extensive research efforts, the complexity of inelastic seismic response and the large number of parameters influencing the behavior of irregular buildings, as compared to their elastic counterparts, lead to a lack of general and universally accepted conclusions. Hence, several studies are still aimed at drawing some definitive conclusions.

Of particular interest are the two papers by Peruš and Fajfar (2002, 2005), since they tackled an issue of a general nature, such as the effects of plastic excursions on torsional response in comparison with the corresponding elastic response.

To draw some general conclusions, the studies were conducted by means of single-storey models with bi-axial eccentricity without any code-design restrictions. The major findings of the parametric analysis, performed primarily on torsionally-stiff mass-eccentric systems (Fig. 1), can be summarized as it follows: from a qualitative point of view, global torsional effects in inelastic structures are similar to the elastic ones (Fig. 2), since differences between elastic and inelastic response are more pronounced in the translational part of motion, rather than in the rotational one. However, quantitatively, the change in response depends on the 
(a)

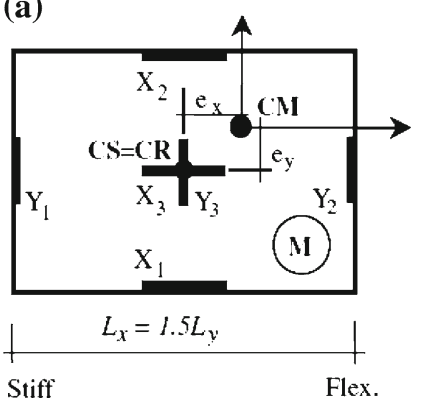

(b)

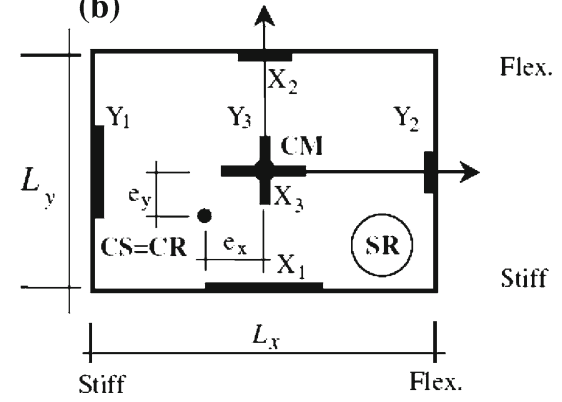

Fig. 1 (a) Mass-eccentric model (M) and (b) stiffness- and strength-eccentric model (SR) used in (Peruš and Fajfar 2005): lateral uncoupled periods of $0.3 \mathrm{~s}$ and $0.4 \mathrm{~s}$, and a torsional vibration period of $0.254 \mathrm{~s}$ are assumed
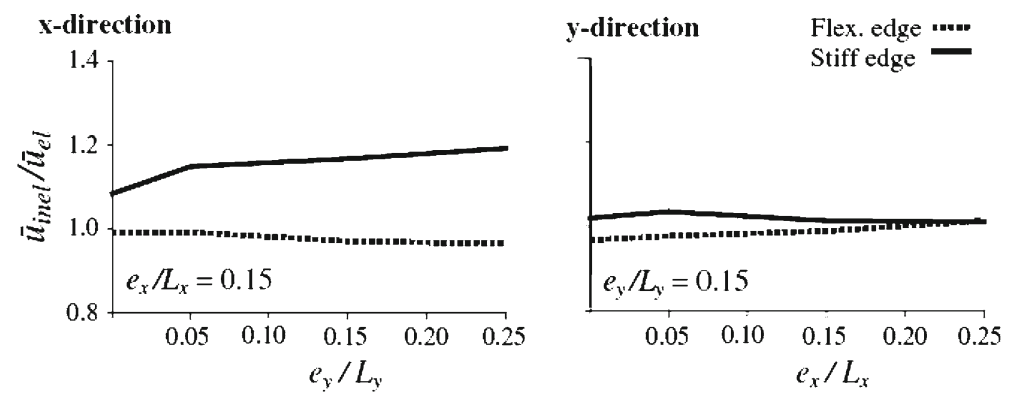

Fig. 2 Ratios between normalized inelastic and elastic displacements obtained by Peruš and Fajfar (2005)

magnitude of inelastic deformations. In particular, normalized inelastic to elastic displacements at the flexible edge generally decrease with increasing ductility, except for very small values (below 2).

Nevertheless, the inelastic torsional response was found to be strongly dependent on the characteristics of the seismic input and affected by greater dispersion than in the elastic range of behavior. In the inelastic range, torsional effects may result to be either larger or smaller than the elastic displacements, depending on the frequency content of the input ground motion. Generally, Peruš and Fajfar (2002) found a decrease for flexible structures and an amplification for stiff structures (short periods range), according to the shape of response spectrum.

It is to be recognised the importance of the issues involved and the correctness of the major findings of the abovementioned papers; however, the parametric analysis needs to be extended to cover variations in torsional stiffness and torsional strength of the building model, since such parameters may influence the relative magnitude of torsional response in the elastic and inelastic range of behavior.

Several studies have aimed to develop more refined one-storey idealizations to account for adequate post-yield behavior of resisting elements. In Dutta and Das (2002a, b), the effects of strength degradation on the bi-directional response of code-designed systems were investigated. The authors proposed the two simple hysteretic models shown in Fig. 3, which can account for stiffness and strength deterioration characteristics of RC structural elements under cyclic loading. Results suggested that local peak demands (on the flexible edge as well 

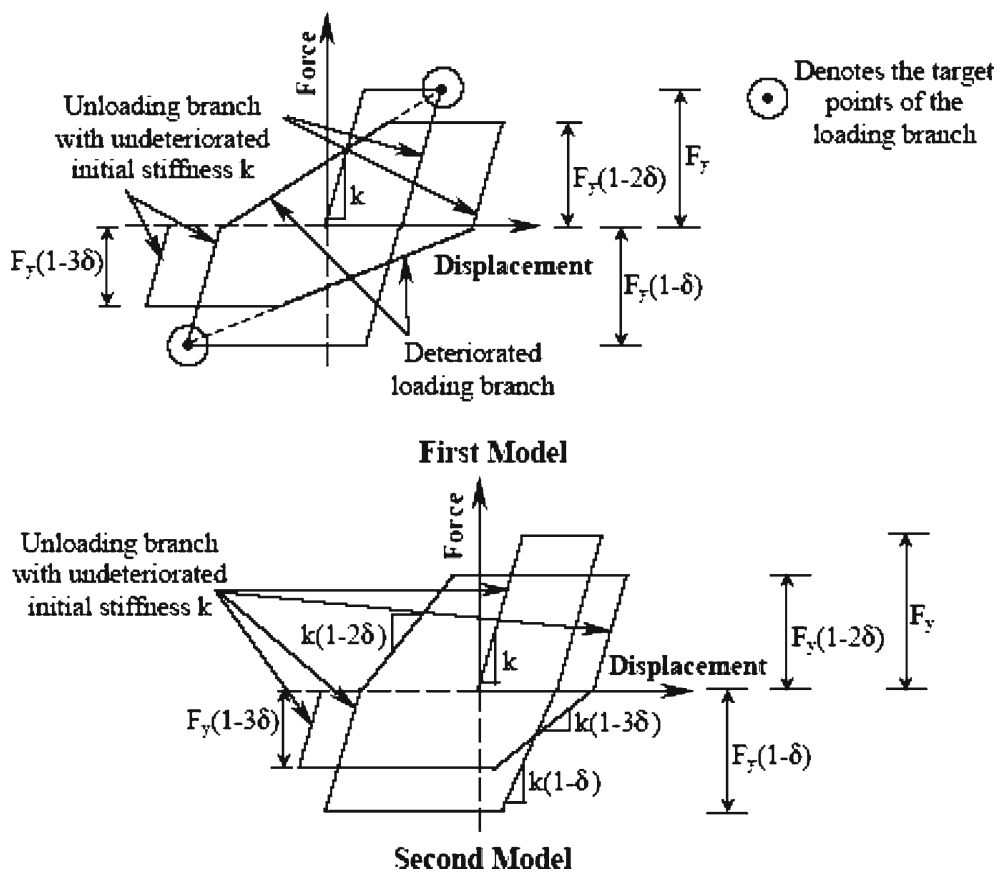

Fig. 3 The stiffness and strength deteriorating hysteresis models used by Dutta and Das (2002b)

as on the stiff edge) are more significant when strength degradation phenomena are taken into account and, in this case, uni-directional analyses consistently underestimate the response. This, however, apparently contrasts with the conclusions of Tso and Myslimaj (2002), who concluded that results from a degrading hysteretic model are similar to those obtained by an elasto-plastic model.

De Stefano and Pintucchi (2002) proposed a single-storey model that takes into account the effects of inelastic interaction between axial force and bi-directional horizontal forces in resisting elements. The influence of such effects on torsional response was evaluated for torsionally-stiff systems under two-component earthquake excitations. The authors concluded that previous models of plan asymmetric structures, which make no allowance for interaction phenomena, generally overestimate torsional response; in fact, inelastic interaction phenomena result in a reduction of floor rotation ranging between $20 \%$ and $30 \%$, except for short periods.

In recent years, Tso and Myslimaj have focused their interest on the implications on seismic design of the interdependence between strength and stiffness in lateral resisting elements (Tso and Myslimaj 2003; Myslimaj and Tso 2005). Many researchers have pointed out that, as yield displacements of resisting elements depend only on the geometry and the material properties, stiffness cannot be considered independent of strength. Tso and Myslimaj studied the problem of resisting elements having strength-dependent stiffness by means of a one-storey model under bi-directional excitations, and they concluded that a desirable distribution of mass, stiffness and strength to reduce torsional response locates the centre of stiffness (CR) and the centre of strength (CV) on the opposite sides of the centre of mass (CM), a condition referred to as 'balanced CV-CR location'. They also proposed two strength design procedures to achieve the described CV-CR location, one based on the use of static 

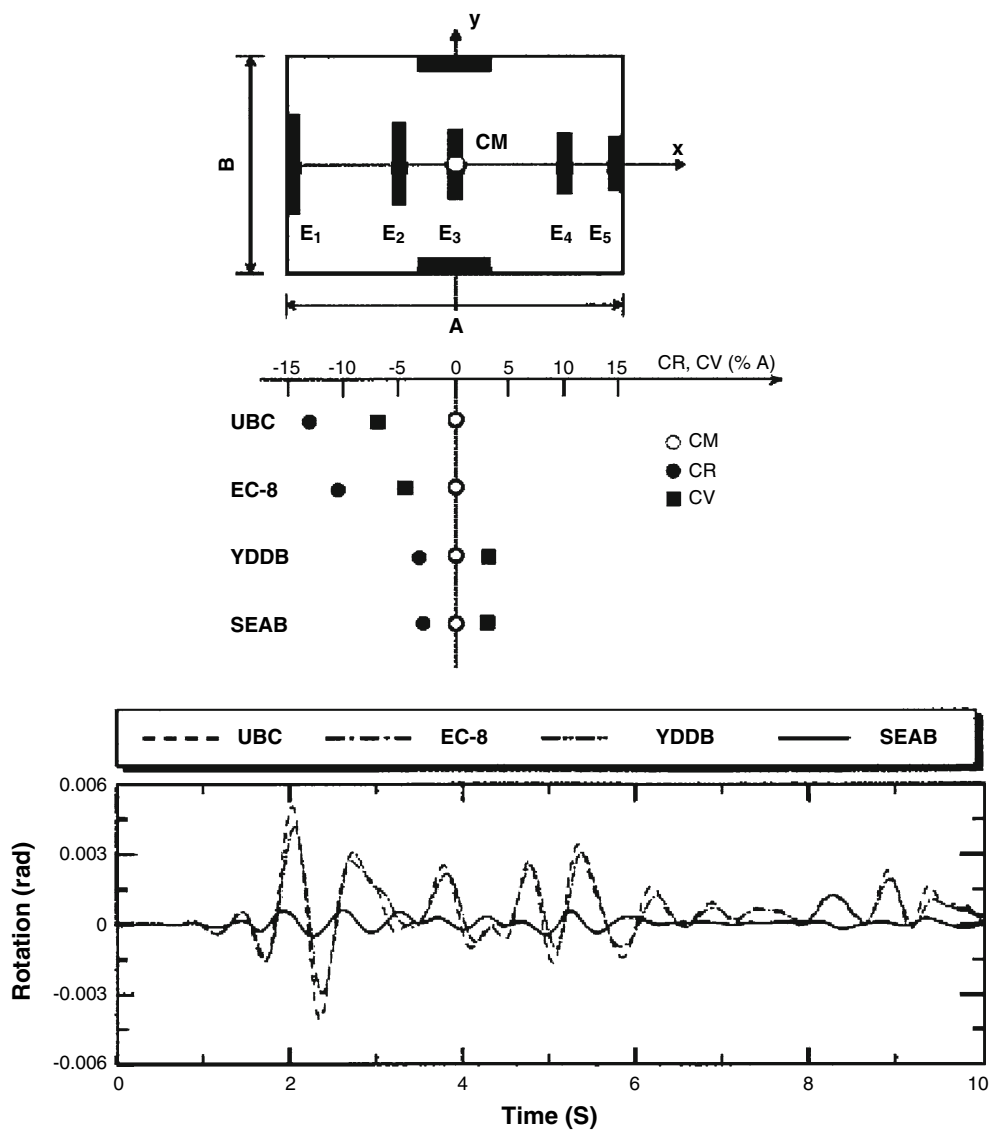

Fig. $4 \mathrm{CR}$ and $\mathrm{CV}$ locations of the four models compared and their deck rotation time histories under bi-directional El Centro earthquake excitations (Myslimaj and Tso 2005)

equilibrium analysis (referred as SEAB) and the other characterized by a strength distribution equal to that of the yield displacements (YDDB procedure). A comparison with results from code-designed systems (Fig. 4) demonstrated the effectiveness of the balanced location.

Strictly correlated with these studies is the paper by Aziminejad and Moghadam (2005), who investigated the nonlinear behavior of irregular code designed single-storey structures in order to optimize configuration of mass, stiffness and strength centers with respect to different levels of plastic excursions in the framework of performance-based seismic design. It turned out that the balanced location proposed by Tso and Myslimaj optimized system response at the life safety performance level (i.e. when the system is subjected to large inelasticity), whereas this was not the case in the elastic range of behavior. Furthermore, it was found that the best configuration varies not only with the assumed performance level, but also with the selected response parameter or damage indices. In this respect, the balanced location did not attain the minor ductility demands to the edge's resisting element.

In their study, Pettinga etal. (2005) analyzed a single-storey model under uni- and bi-directional earthquake excitations. Their aim was to extend to 3D plan asymmetric buildings the proposed performance based-design framework, which emphasizes the importance of 
assessing and limiting residual deformations. Parametric analyses on mass eccentric systems were carried out in order to identify the main parameters influencing the residual deformations/displacements. Different layouts in plan, leading to either torsionally restrained or unrestrained systems, according to Paulay's definition (Castillo et al. 2002), were primarily considered. Contrary to expectations, their findings suggested that systems with low torsional restrain improved residual rotation behavior. Further investigations were also presented to evaluate the effects of hysteretic characteristics, post-yielding stiffness ratio, P-delta effects, and seismic intensity.

Trombetti and Conte (2005) developed a simplified procedure (called the ALPHA method) for estimating the maximum rotational response under free and forced vibrations of onestorey linear elastic systems. The predictive ability of the method, initially formulated for asymmetric seismic isolated building structures, has been successively verified when applied to systems representative of generic plan-asymmetric structures (Pintucchi et al. 2005).

In Heredia-Zavoni and Machicao-Barrionuevo (2004), a linear one-storey bi-asymmetric system was used to evaluate the effects of the orthogonal components of earthquakes. It was found that such effects vary differently with the natural translational period, depending on whether the system is torsionally flexible or stiff, as well as with soil conditions. In particular, application of bi-directional inputs may appreciably affect the response of torsionally stiff systems with long translational periods on soft soils, while on firm soils, conversely, it turns out to be important for torsionally flexible systems with short translational periods. In this respect, however, it should be recalled that, despite the indications of several previous studies, the effects of the orthogonal component of earthquakes do not seem to be really substantial (Rutenberg 2002), especially if orthogonal elements are included into the model.

Lastly, among the few contributions reporting experimental results, the study by Ghobarah et al. (2005) should be mentioned, which deals with the special problem of nonstructural components and critical equipment or installations (secondary systems) attached to a masseccentric primary system, by using a small-scale shake table. From the test results, it was found that torsional yielding of the primary system has significant implications on the magnitude of near tuned secondary systems response.

\section{Multi-storey plan-asymmetric structures}

Although single-storey models represent the most extreme idealization of plan irregular buildings, they have been widely used in the past due to their capability of clarifying the influence of the governing parameters and derive effective design criteria. However, in recent years multi-storey building models have become increasingly popular for at least two good reasons: (1) shortcomings of one-storey models in predicting torsional behavior of real structures have been evidenced by several authors, such as Stathopoulos and Anagnostopoulos (2002, 2003), who critically discussed the effectiveness of such models; (2) development of powerful computational tools has made extensive and refined numerical analyses of 3D multi-storey building structures feasible.

Most studies performed on multi-storey building structures are aimed at extending pushover analysis to plan asymmetric building structures. Early research dates back to the mid 1990s, with the investigations by Kilar and Fajfar (1997) and Tso and Moghadam (1997).

In 2002, Fajfar et al. proposed an extension to 3D models of the N2 method by applying a height-wise distribution of lateral forces to the floor centre of mass. The method, initially formulated for planar (2D) structures, consists of a simplified nonlinear approach that makes use of pushover analysis, equivalent SDOF system and inelastic response spectrum. The 


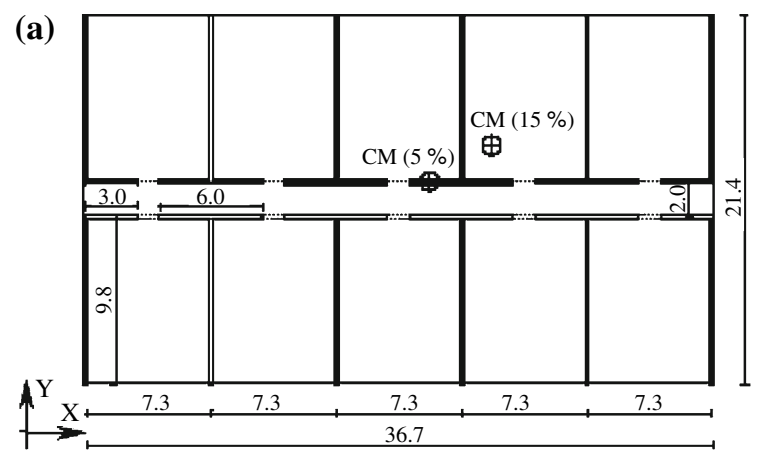

(b)

S

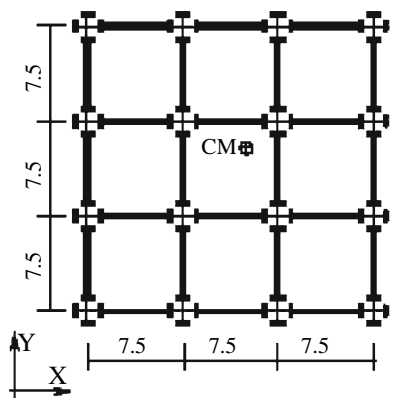

F1

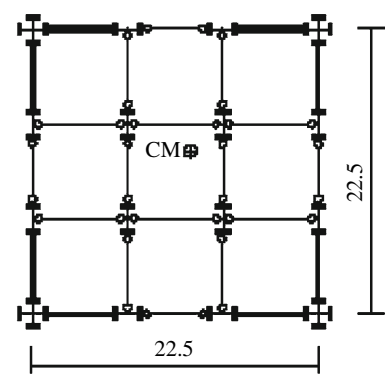

Fig. 5 (a) Floor plan of 8-storey RC wall building: two asymmetric structures were created by displacing center of mass in both horizontal directions by $5 \%(\mathrm{~W}-5)$ and 15\% (W-15); (b) floor plans of the analyzed 5 -storey moment-frame steel buildings ( $\mathrm{S}$ and F1): bi-axial asymmetry was introduced by assuming mass eccentricity equal to $15 \%$ of the plan dimensions (Fajfar et al. 2002)

suitability of the extended procedure was demonstrated by investigating both multi-storey steel frame buildings and multi-storey RC buildings with structural walls (see Fig. 5 and Kilar and Fajfar 2002). A comparison with results obtained by nonlinear dynamic analysis evidenced the ability of the method to predict seismic behavior of torsionally stiff structures. Sources of inaccuracy have also been identified as follows: approximations already present in predicting 2D behavior, no allowance for dynamic effects of lateral-torsional coupling, uncertainties in combining results obtained from independent pushover analyses in the two horizontal directions. However, the N2 method turns out to be conservative, since overestimation of displacement at the center of mass prevails over underestimation of torsional effects.

More recently, an important step forward to properly including torsional effects has been made by Fajfar etal. (2005), who proposed combining the results obtained by pushover analysis of a 3D structural model, based on the N2 method, with the results from a linear dynamic (spectral) analysis. The N2 method controls the target displacements and distribution of deformations along the height of the building, whereas the linear dynamic analysis is used to define the torsional amplifications of lateral displacements. Use of linear dynamic analysis was justified by the assumption that, at the flexible edge, the elastic envelope of lateral displacements is conservative with respect to the inelastic ones (Peruš and Fajfar 2005).

An alternative pushover procedure proposed by Moghadam and Tso (2000) consists of two steps: (1) a 3D elastic response spectrum analysis to determine roof displacements and the distribution of lateral forces for each resisting elements; (2) a planar pushover analysis 
for each resisting element with the lateral force distribution and target displacement defined in step 1).

Chopra and Goel (2004) sought to extend the modal pushover analysis proposed in (Chopra and Goel 2002), by applying torsional moments at each floor (to account for dynamic effects of torsional response) in addition to lateral forces, all of them obtained from modal analysis. A comparison of predictions from the proposed procedure to exact values determined by nonlinear modal response history analysis was conducted for four structural systems with different values of the ratio of uncoupled lateral to torsional vibration periods. Results demonstrate an accuracy in response of the modal pushover analysis similar to that for a symmetric building. However, the results deteriorate for systems with stronger coupling of elastic modes, in part due to underestimation of roof displacement by the CQC modal combination rule, which occurs because the individual modal responses attain their peaks almost simultaneously. Structural plan-asymmetry about both axes and simultaneous action of two horizontal components of ground motion also remain to be investigated.

Penelis and Kappos (2005) also aimed at modelling the inelastic torsional response of buildings in nonlinear static (pushover) analysis. The proposed method consisted of a 3D pushover analysis, applying spectral load vectors defined from dynamic elastic spectral analysis; moreover, response quantities were obtained through a generalized equivalent SDOF system, which incorporates both translational and torsional modes. The proposed procedure was verified for few case studies: two single-storey and two multi-storey mono-symmetric buildings. In the first case, the deviation of the proposed methodology from the mean response resulting from nonlinear dynamic analysis was around $10 \%$, while in the case of multi-storey buildings the difference in the response was about $20 \%$, also considered acceptable given the uncertainties in the inelastic response of three-dimensional nonlinear models.

Of the procedures described above, the one proposed by Fajfar et al. (2005) appears to be the most promising, as its definition of target displacement of the mass centre accounts for actual inelastic behavior through the N2 method, and amplifications of lateral displacements are simply obtained through linear modal analysis.

Some other papers have dealt with seismic design procedures for asymmetric buildings in agreement with performance-based design procedures, such as (Ayala and Perez 2005), whereas several papers have investigated some behavioral aspects of asymmetric multi-storey building structures. Stathopoulos and Anagnostopoulos (2005) presented one of the first attempts to study torsional response in the nonlinear field by means of the more realistic frametype multi-storey building models, contrary to most previous papers that refer to one-storey and/or shear-beam type models. More specifically, they investigated the inelastic earthquake response of eccentric multi-storey $\mathrm{RC}$ frame buildings by means of three and 5-storey models subjected to bi-directional motions. Buildings designed according to both the EC8 provisions and the UBC-97 code were considered. Results suggested to the authors that frames at the flexible side experience increased inelastic deformations, while those at the stiff side decreased deformations with respect to their symmetric counterparts. Although admitting that further study is needed, they concluded that such uneven distribution of demands is certainly an indication that current codes need re-examination. Moreover, these findings contradict those obtained from single-storey models, which are considered inadequate for predicting the main qualitative features of the inelastic response for multi-storey structures.

Further confirmation of the impossibility of directly extending results from one-storey models to multi-storey structures comes from De Stefano etal. (2006), who presented a study of a code-designed 6-storey framed building subjected to uni-directional records. The paper examines the effects of overstrength in element cross-sections. It was shown that in actual buildings this characteristic may lead to distribution of ductility demands different from 

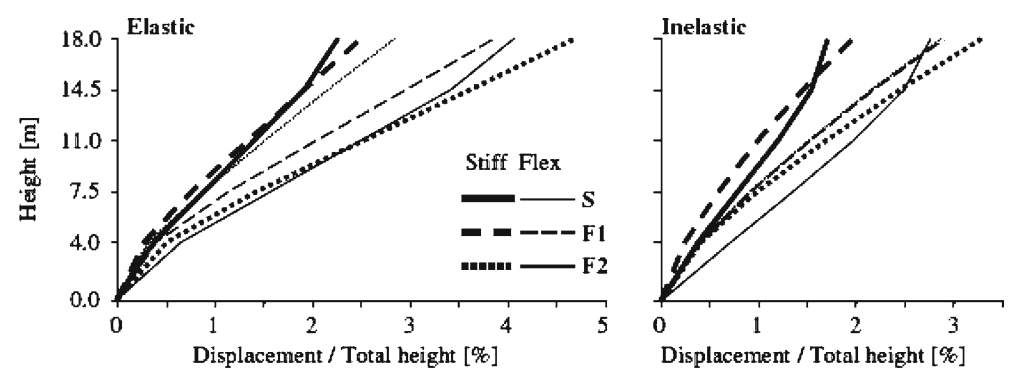

Fig. 6 Displacement profiles at the stiff and flexible edges of the analyzed asymmetric buildings S, F1 and F2 (the former two presented in Fig. 5b) (Marušic and Fajfar 2005)

those expected according to results from single-storey models. In particular, De Stefano et al. (2006) also found that, in the upper floors, the larger ductility demands occur at the building flexible side, compared to those at the stiff side.

Marušic and Fajfar (2005) investigated the elastic and inelastic response of massasymmetric multi-storey steel frame buildings under bi-directional ground motions. According to Peruš and Fajfar (2005), results evidenced a qualitatively similar elastic and inelastic response, as shown by Fig. 6, with the exception of the stiff edge in the direction undergoing lower plastic deformations in torsionally stiff buildings, and, the same edge, though in the weaker direction, in torsionally flexible ones.

Fernandez Davila and Cruz (2006) studied the influence of several parameters on seismic response by using simple three-dimensional 5-storey building models, which can be considered direct extensions of the one-storey building models widely used in the past. The effects of the following system parameters were investigated: number of resistant planes parallel to the earthquake action, degree of torsional coupling, uncoupled fundamental vibration period, normalized static eccentricity, uncoupled lateral frequencies ratio, torsional stiffnesses ratio, and overall design ductility. Most of their conclusions confirm well-known behavioral trends in asymmetric structures.

Sommer and Bachmann (2005) addressed the seismic design of plan-asymmetric multistorey buildings, stiffened with ductile RC structural walls from a very practical point of view. After a critical overview on the deficiencies of design rules proposed by current codes, they focused on the main issues that should be dealt with: (1) element stiffness is not independent of strength (Fig. 7), as already mentioned by (Tso and Myslimaj 2003; Paulay 2002), (2) a realistic plan-wise distribution of strength according to actual RC wall properties, in terms of reinforcement percentage, almost never satisfies a criterion for optimal location of the strength centre-with respect to the centers of mass and stiffness-previously developed. Therefore, a new strength and stiffness distribution criterion was suggested in order to obtain uniform distribution of ductility demands with realistic reinforcement quantities in resisting elements. A case study was detailed in order to demonstrate how the new criterion can be used within a refined earthquake-equivalent lateral force method.

In De-la-Colina (2003), several codes recommendations for torsionally unbalanced multistorey buildings design based on simple static procedure were assessed. Investigation was conducted on several 5-storey buildings with both mass and stiffness eccentricity. Resisting elements were assumed to be nonlinear shear-beam models, and were excited by two El Centro earthquake components acting simultaneously. Seven static design procedures were assessed and optimal values for storey eccentricities found. 

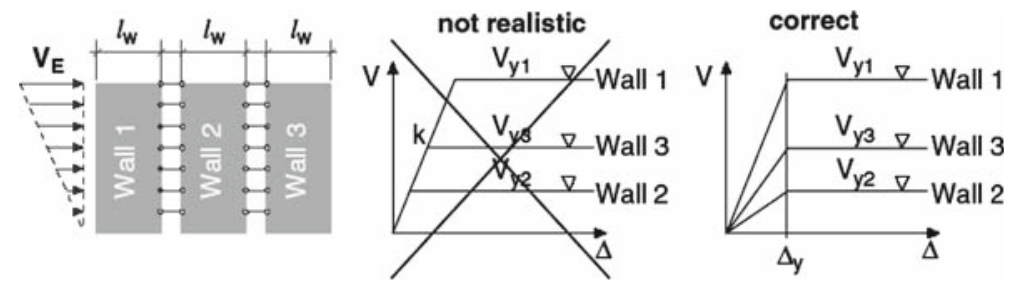

Fig. 7 Force-displacement relationship of RC walls used in Sommer and Bachmann (2005)

Lastly, in the experimental field Negro et al. (2005) conducted pseudo-dynamic tests of a real-size plan-wise irregular 3-storey frame structure, both in the 'as-built' and in two retrofitted configurations. The research was carried out within the framework of the activities of the ELSA Laboratory of the Joint Research Centre. The structure was a regularly asymmetric multi-storey simplification of an actual building representative of old constructions in Southern European Countries, without specific provisions for earthquake resistance.

Experimental data was presented with particular focus on highlighting torsional effects on the seismic response of the specimen by successfully applying the Karhunen-Loève modal decomposition analysis.

\section{Passive control systems for asymmetric structures}

The application of passive control to irregular building structures is an appealing strategy, and has thus become a very popular research field. In this review, the available literature has been grouped into four categories: (1) papers dealing with the behavior of asymmetric structures equipped with viscous, fluid viscous and visco-elastic dampers; (2) papers dealing with optimum design of supplemental dampers; (3) papers dealing with other types of damper devices; (4) papers dealing with base isolation.

Starting with the first category, early papers were published towards the end of the 1990s by Goel, who studied the response of one-storey asymmetric structures with linearly elastic vertical resisting elements, equipped with supplemental fluid viscous dampers (FVD). The effectiveness of damper devices in reducing edge deformations was investigated, as well as their effects on the systems modal properties (Goel 1998, 2000). Lin and Chopra (2001) also provided more insight into the problem of how and why plan-distribution of FVD influences the response of linearly elastic one-storey asymmetric systems. They concluded that appropriate asymmetric distribution of devices can be twice as effective in torsional response mitigation (as compared to a symmetric one).

The next step in the research consisted of considering asymmetric-plan systems responding in the inelastic range of behavior (Goel and Booker 2001). The emerging picture is similar to that noted previously for linear elastic systems: optimal plan-distribution of additional damping is effective in reducing not only deformation demands, but also ductility and hysteretic energy dissipation demands in resisting elements.

In recent years, Lin and Chopra have investigated the earthquake response of asymmetric one-storey elastic systems with nonlinear FVDs attached in series to a linear brace, as shown in Fig. 8 (Lin and Chopra 2003a). It was found that supplemental damping nonlinearity and bracing flexibility influence system response only slightly (in terms of flexible and stiff edge deformations and floor rotations). Therefore, nonlinear viscous and visco-elastic dampers achieve essentially the same reduction in torsional response as linear dampers. However, 
(a)

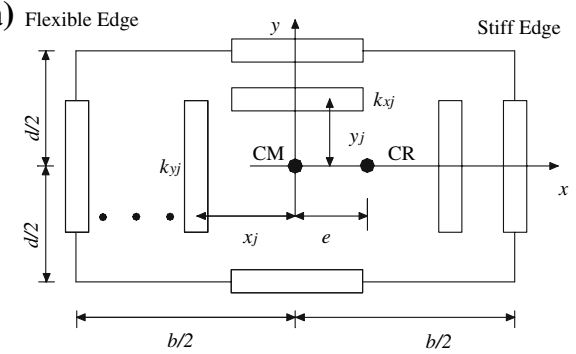

(b)

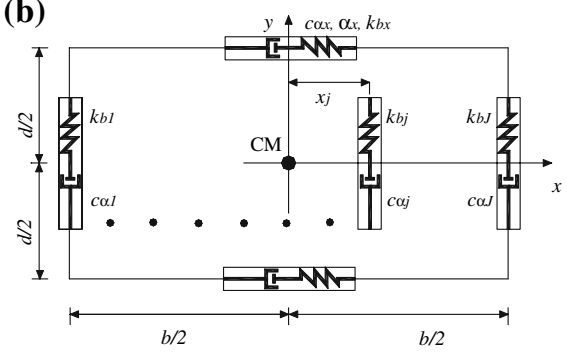

Fig. 8 (a) Resisting elements and (b) supplemental nonlinear viscous and/or visco-elastic dampers of systems (after Lin and Chopra 2003a)

they limit excessive damper forces at large structural velocities, and are therefore better suited than viscous dampers. For design applications, the authors indicate that the effectiveness of nonlinear FVDs and their plan-distribution can be predicted by advantageously replacing nonlinear dampers by energy-equivalent linear viscous dampers. In this respect, the error in estimating the values of structural parameters from the corresponding linear system has also been investigated in (Lin and Chopra 2003b). Results evidenced the accuracy in linear prediction of response (again in terms of edges deformations and floor rotations) in the velocity and displacement-sensitive regions of the spectrum, while linear prediction was found less accurate as the structural period becomes lower, and bracing effects, if present, become weaker. Instead, the approximation due to the adoption of energy-equivalent linearization was not affected by system eccentricity. Similar trends were observed in predicting pseudo-velocity of the nonlinear dampers, although peak forces of devices could not be estimated in this way. Lastly, a modified response spectrum analysis, proposed in a previous work for nonclassically damped systems, was considered suitable even for systems with nonlinear dampers.

Turning now to papers addressing the optimum design of supplemental dampers (i.e. for their optimal magnitude and plan-wise location), Kim and Bang (2002) proposed a methodology to identify the optimal eccentricity of supplemental dampers (ODE), i.e. the eccentricity that makes the edges displacements identical, which is based on modal characteristics of the system, and thus applicable only in the linear elastic range of structural behaviour. The ODE can be determined via modal analysis - by minimizing the ratio between the rotational and lateral components of the fundamental mode. Furthermore, for practical purposes, the authors directly furnished an ODE diagram, which provides the optimum eccentricity of dampers for a given system stiffness eccentricity, frequencies ratio and damping ratio (of the corresponding symmetric system). It is worthwhile noting that they addressed only optimization of plan-wise location of devices, as total damping is to be determined independently. Moreover, results suggested once again the beneficial effect of an asymmetric plan-wise distribution of devices and, confirmed that visco-elastic devices are superior to viscous dampers. The observed influence of visco-elastic dampers (VED) in changing both the natural frequencies and the modal damping ratio of the structure gave Lee etal. (2004) the idea of developing a procedure for determining the optimum amount and location of visco-elastic dampers. The method consists of two steps: (1) firstly, natural frequencies and modal damping ratio that can achieve a certain target displacement—or minimize the maximum one-are obtained through the convex model; (2) then, the desired dynamic properties are obtained by an optimum distribution of VED throughout a procedure involving the gradient of the eigenvalues. 
Although the visco and visco-elastic devices have been the most widely studied, some papers refer to other types of devices. De la Llera et al. (2005) considered frictional dampers more effective than other type of devices for passive control in asymmetric systems, as they enable dissociating stiffness and strength. They proposed an optimizing procedure, within the framework of the torsional balance concepts. Referring to its weak definition, which requires equal mean square values of the displacement demands in resisting elements located symmetrically in plan, frictional dampers led to achieve torsional balance by placing the centre of balance (EBC) equidistant from the building edges. More dampers can be eventually added by maximizing the centrifugation, leaving the EBC location unchanged.

After Singh etal. (2002) addressed optimum design of tuned mass dampers for passive control of torsional building systems, the effectiveness of multiple tuned mass dampers (MTMD) was studied by Wang and Lin (2005), who also considered soil-structure interaction effects. Based on a modal analysis investigation, the authors concluded that the effectiveness of MTMD is actually dependent on the soil-structure interaction effects, which should be accounted for when irregular structures are built on soft soils.

The possible use of innovative "smart" materials for the purpose of controlling asymmetric structures is also an emerging area of research. Yoshida et al. (2003) proposed semi-active control systems with magnetorheological (MR) dampers. The performance of such devices was experimentally verified using a two-storey frame asymmetric building equipped with two MR dampers between the first floor and the ground, as illustrated in Fig. 9. Results were satisfactory from an experimental point of view, though the cost issues of making such devices actually useful in practice remain to be addressed.

The fourth group of papers surveyed deals with base isolation. In the two papers (Tena-Colunga and Gomez-Soberon 2002; Tena-Colunga and Zambrana-Rojas 2006), the authors investigated separately the effects of the superstructure eccentricity and the isolation system eccentricity on the base-isolated system torsional response, with particular emphasis on peak response for the isolation system, i.e. maximum isolator displacement and ductility demand. Both nonlinear investigations were carried out by a 3-storey rigid building model with bilinear elastomeric isolators, subjected to a set of real uni- and bi-directional input ground motions. They found that variations in peak response are dependent on the amount of superstructure eccentricity (given by a shift of mass), and concluded that the effectiveness of base-isolation for torsionally coupled systems decreases with increasing eccentricity. Only the influence of mass eccentricity was investigated, while torsional to lateral frequency ratio was kept constant (equal to 1.2) (Tena-Colunga and Gomez-Soberon 2002). The second paper, in which the torsional response is due exclusively to isolator stiffness eccentricity-a situation which is less realistic because in principle no one would design an asymmetric isolation system having a symmetric superstructure - appears rather less interesting, though, in any event, it substantially confirmed the trends highlighted in the previously mentioned work.

With the aim of obtaining design indications, Ryan and Chopra (2004) also investigated peak deformations among all the isolators of the asymmetric-plan base-isolated buildings models shown in Fig. 10. Using nonlinear analyses they obtained results for various values of global parameters of the isolation system, by applying bi-directional ground motions. Their findings evidenced that deformation of a corner isolator increases with the stiffness eccentricity, whereas it depends only weakly on period, strength and torsional-to-lateral frequency ratio of the isolation system. As a result, an equation which involves only stiffness eccentricity and distance from the centre of mass to the outlying isolator was provided in order to predict the largest deformation of isolators. Lastly, because of the significant increase in displacements found in their investigations, the authors concluded that peak isolator deformations highly underestimated by the IBC code provisions. 


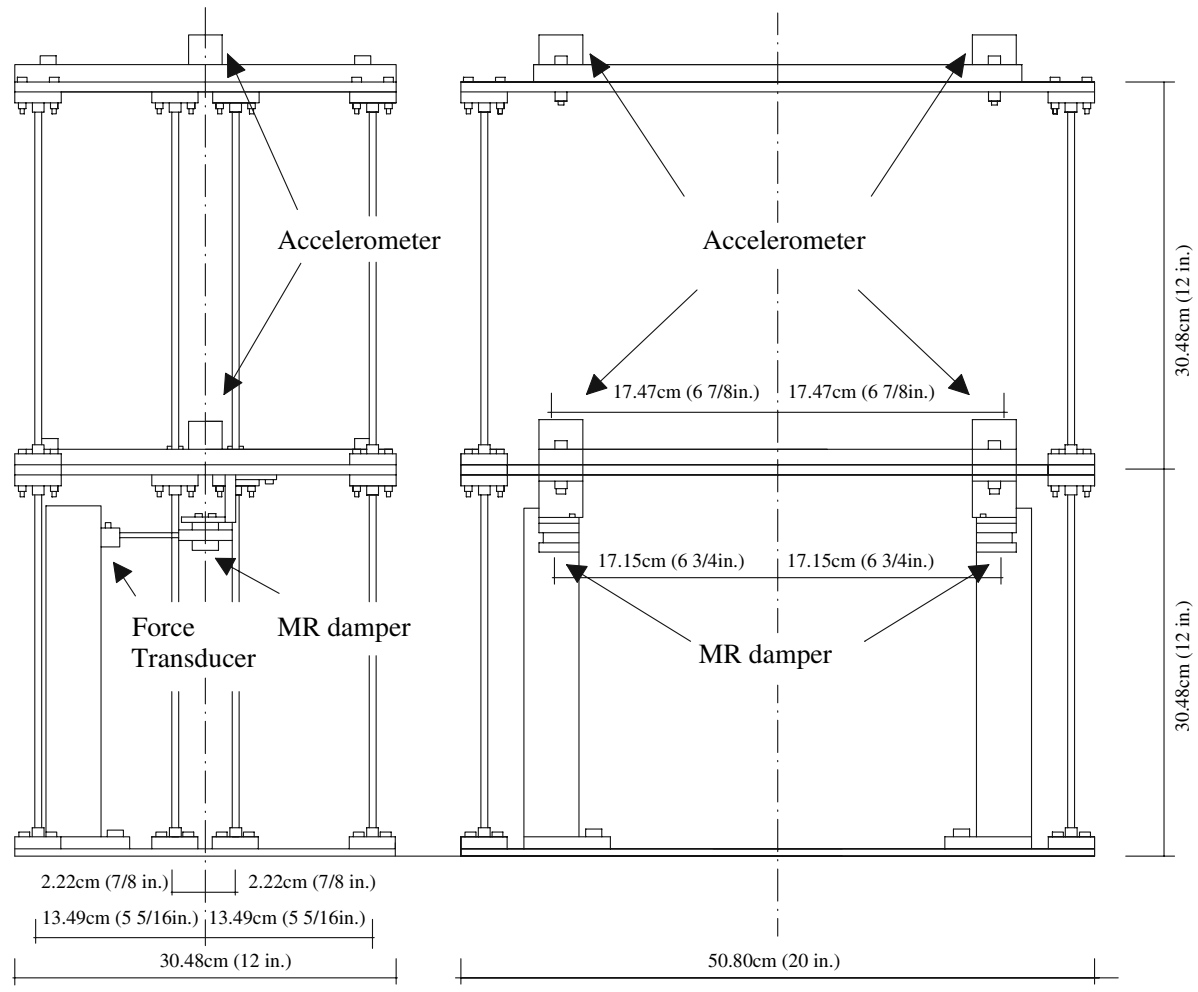

Fig. 9 Schematic view of test structure (after Yoshida et al. 2003)

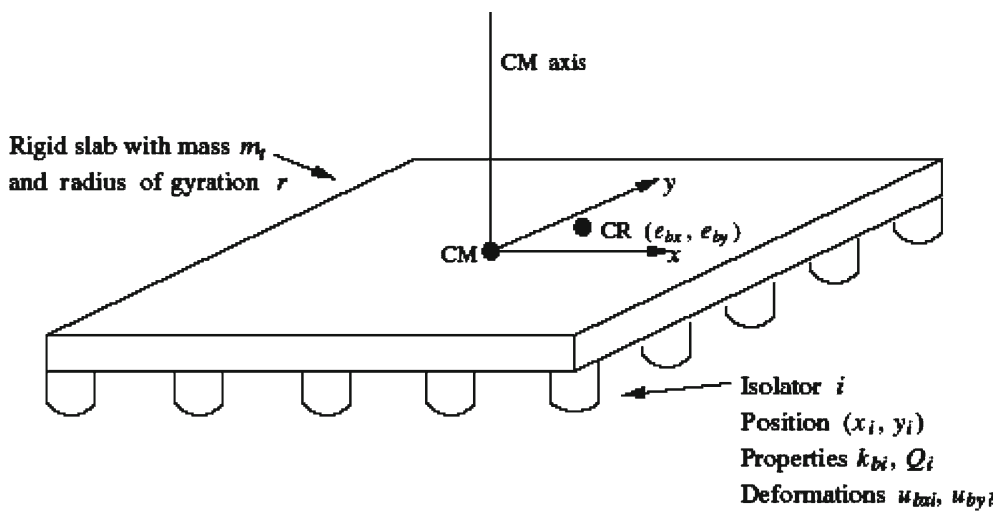

Fig. 10 Model used by Ryan and Chopra (2004)

In Shakib and Fuladgar (2003), the effects of earthquake vertical components on the response of pure-friction base-isolated asymmetric structures were investigated. Structure was idealized as a three-dimensional single-storey building resting on sliding supports. Results from an extended parametric analysis pointed out that the effectiveness of such devices in reducing torsional effects may be overestimated by considering only bi-directional ground motions. In particular, torsional response in the low range of eccentricity increases 
considerably due to earthquake vertical components. Nevertheless, the conclusions were based on application of records from Northridge earthquake which are notoriously characterized by large vertical peak ground acceleration.

De la Llera and Almazan (2003) presented an experimental study on mass-asymmetric 3 -storey-eccentric structures isolated with friction pendulum dampers (FPS). The aim of the work was to evaluate the efficacy of the FPS isolators and provide data for analytical studies. The testing program also dealt with nominally symmetric structures which develop lateral-torsional coupling under bi-directional excitations due to variation in normal loads in frictional pendulum and, hence, in the strength plan-distribution.

This coupling, denoted by the authors as accidental torsion due to overturning, was investigated by Almazan and De la Llera (2003) by means of the building model shown in Fig. 11. From their results it emerges that little torsional amplifications at the base occur due to this phenomenon, so that increases in deformations could probably be neglected for design purposes of the isolation system. In contrast, accidental torsion may lead to significant torsional amplification in the interstorey deformations of the superstructure.

Lastly, Murnal and Sinha (2004) proposed a variable frequency pendulum isolator (VFPI) system to use in torsionally coupled structures as an effective alternative to pure friction and friction pendulum systems.

\section{Vertically irregular structures—setback multi-storey buildings}

Design of public buildings such as theatres and museums as well as monuments is commonly dictated by either aesthetic or functional considerations that often preclude the simplicity of less important buildings. As a result, the shape of the majority of such structures is irregular, both in plan and in elevation (Reinhorn et al. 2005).

In comparison with research efforts dealing with horizontally irregular structures, studies aimed at predicting the behavior of structures with uneven layouts in elevation are small in number. Nevertheless, in recent years research activity in this field has been growing.

Since the late 1990s, several studies investigated behavioural aspects of setback structures and limitations of seismic code provisions for such class of buildings. To recall just a few, Duan and Chandler (1995) pointed out that both static and modal spectral analyses were inadequate to prevent damage concentration in members near the setback level, while Kappos and Scott (1998) noted that there was a lack of conclusive evidence on the location of possible damage concentration for this class of buildings.

More recently, most of the studies still aim at a better understanding of the seismic response of irregular buildings in elevation in order to obtain information useful to assessing suitability of: (i) code criteria that distinguish between vertically regular and irregular structures and, (ii) special rules provided for the latter ones, which in general consist of decreasing the behavior factor and imposing modal analysis instead of the equivalent static one.

Almost all studies in the field refer to frames with flexible beams, rather than simpler shear-type frame models as used in the past. Nevertheless, they deal almost exclusively with $2 \mathrm{D}$ frames or plane frames extracted from 3D, fully plan-symmetric or mono-symmetric structures - so that torsional effects do not arise. Das and Nau (2003) investigated a relatively large set of RC buildings with different number of storeys, types and locations of vertical irregularities, as shown schematically in Fig. 12. Starting from the belief in usefulness of simplified procedures for seismic design, the paper focused on seismic codes, such as the UBC, which make restrictions on the applicability of simplified design methods-i.e. the equivalent lateral force method (ELF) - for structures with consistent vertical irregularities. To check 

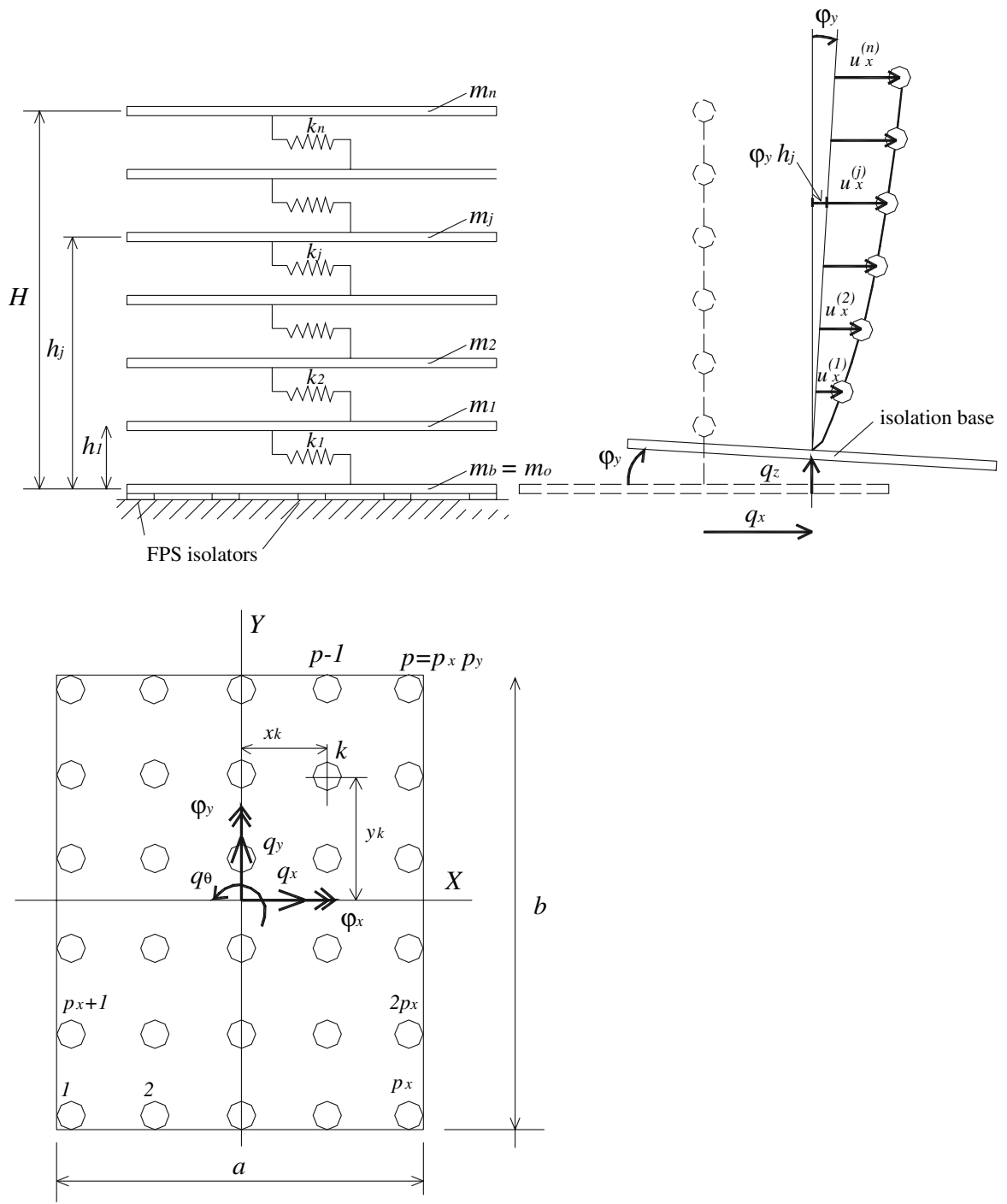

Fig. 11 Building idealization (after Almazan and De la Llera 2003)

the suitability of such code limitations, seismic response of building models with lateral resisting elements designed via the ELF method were evaluated by $2 \mathrm{D}$ linear and nonlinear dynamic analyses. Results pointed out that most structures performed well when subjected to the design earthquake, suggesting that limitations on the applicability of simplified design procedure are unnecessarily conservative for certain types of vertical irregularities.

The aim of Tremblay and Poncet (2005) was again to determine whether or not dynamic analysis is really needed for vertically irregular structures, as stipulated by major seismic codes. However, they focused particularly on buildings with mass irregularity, as shown in Fig. 13: seven 8-storey, concentrically braced steel framed structures with different mass discontinuity patterns were designed according to the current NBCC provisions-through 


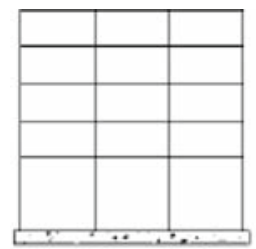

Type A

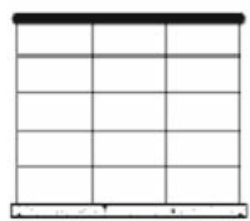

Type $\mathrm{t}$

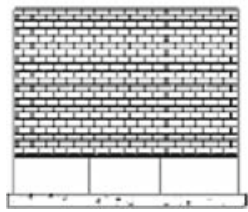

Type E1, E2

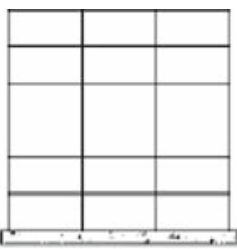

Type B

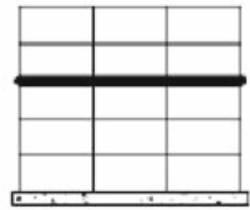

Type $m$

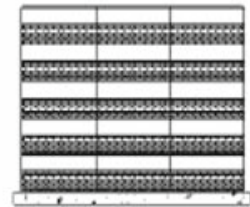

Type E3-E6

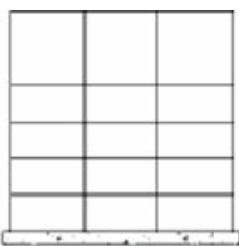

Type C

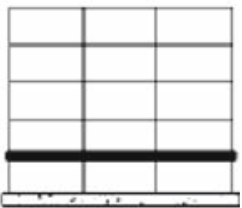

Type b

Fig. 12 Types and locations of vertical irregularities analyzed in Das and Nau (2003). Buildings were investigated with a taller first, intermediate or top storey (Types A, B, C), with irregular mass distribution (Types t, $\mathrm{m}, \mathrm{b}$ ), partial infill (Types E3-E6) and open ground floor (Types E1, E2)

both the equivalent static force and the response spectrum procedures. On the basis of results obtained by 2D nonlinear dynamic analysis under code-compatible input ground motions, the authors concluded that even strong mass irregularity of structures designed with static analysis does not result in significant negative effects on their seismic response. In addition, adopting a dynamic analysis method in design does not significantly improve seismic performance, as the peak storey drifts obtained are similar regardless of the design procedure used.

Tena-Colunga (2004) studied two irregular (setback and slender) 14-storey RC moment resisting framed buildings, with one or two-bay frames in the slender direction. In this case, structures were designed close to the limiting drift angle of $1.2 \%$, established by the Mexican code. Results obtained through nonlinear dynamic analyses suggested that the slender direction of setback buildings with one-bay frames is vulnerable, contrary to what occurs if a bay is added in the slender direction thanks to the higher redundancy in framed structures. The author concluded that seismic codes should penalize seismic design of buildings with single-bay frames in one direction.

Magliulo et al. (2002) focused on 5- and 9-storey RC frames designed according to EC8 provisions for the "low" ductility class. Vertical irregularities due to different distributions of either mass, stiffness or strength were treated separately. In addition, the suitability of criteria provided by many codes in order to detect irregularity in elevation was verified by investigating the actual increase in inelastic demands of the analyzed models as compared to their regular counterparts, as well as any deterioration of seismic performance. Results suggested that criteria specified by major international codes are unable to identify the regular or irregular status of a building, especially in the presence of irregular distributions of masses and 


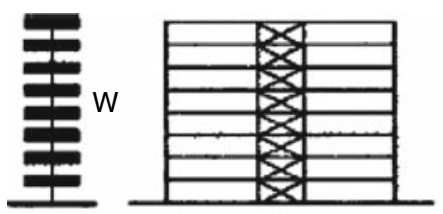

R8-200-100

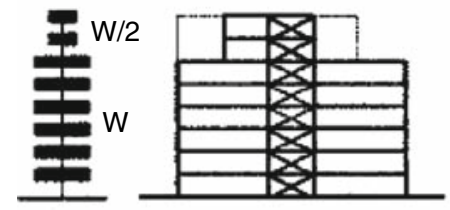

18-200-75

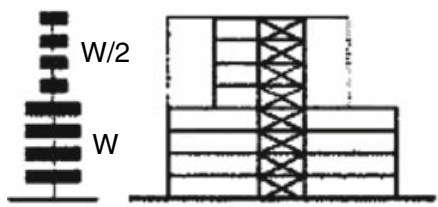

$18-200-50$

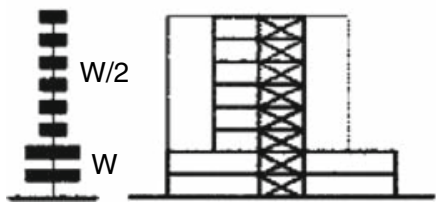

18-200-25

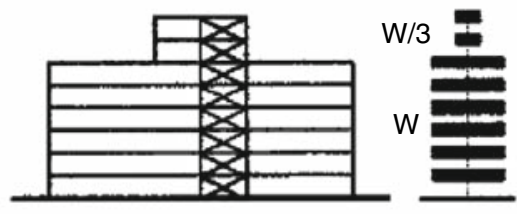

18-300-75
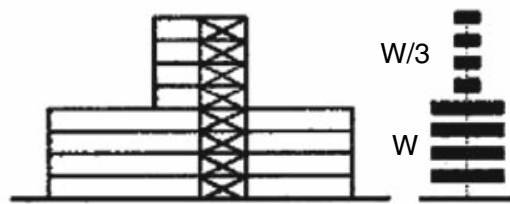

$18-300-50$

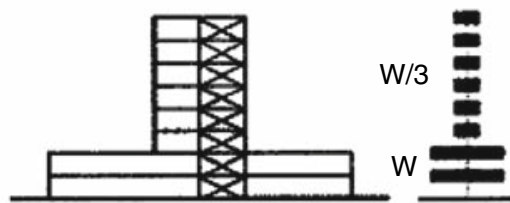

18-300-25

Fig. 13 Side elevations and mass distributions along the height of buildings analyzed by Tremblay and Poncet (2005)

strengths. Regarding mass irregularity, their finding, i.e. variations in mass do not necessarily result in increase in plastic demands, is consistent with conclusions from other researches (e.g. Tremblay and Poncet 2005). With regard to strength irregularity, it was found that only overstrength of beams results in increased plastic demands, while overstrength in columns, and its variation along the building height, causes almost negligible effects. Therefore, code criteria, such as those subscribed by EC8 and IBC, based on variations of storey strength-a parameter mainly dependent on column strengths - fail to detect strength irregularity.

Athanassiadou and Bervanakis (2005) analyzed, through nonlinear dynamic analysis, two multi-storey RC frame buildings with large setbacks in the upper storeys, again designed according to the EC8 provisions but for the "high" ductility class. Differently from the foregoing paper, the hierarchy of strengths procedure was taken into account and therefore column overstrength was introduced. Results evidenced satisfactory seismic performance, characterized by the formation of plastic hinges in beams, suggesting that capacity design procedure provided by EC8 was successful.

Several other studies have addressed the issue of vertical irregularity in the context of steel frame buildings. Khoury et al. (2005) considered four 9-storey asymmetric setback perimeter frame structures - designed according to the Israeli steel code SI 1225 (1998) - that differed from each other in the location of the setback along the height. To assess seismic response 
with special attention on the influence of the setback level, nonlinear dynamic analyses were performed, and a 3D structural model was used under bi-directional ground motions. Results showed an amplification in response at the upper tower storeys, thus suggesting that the higher vibration modes have significant influence, particularly the torsional ones. In this respect, the authors recommended that future research on setback buildings should be conducted on full plan-asymmetric structures. It is worthwhile noting that, like the work of Bosco et al. (2002), the study conducted by Khoury et al. is one of a very few that address the issue of the effects due to combination of plan and vertical irregularities, a topic that still calls for considerable future research.

Fragiadakis etal. (2005) provided further data on the influence of the vertical irregular distribution of stiffness and strength in steel frame structures, with particular emphasis on structural capacities, rather than on seismic demands. The effects were found to vary depending on the type of irregularity, the storey where irregularities were located and, finally, the intensity of the earthquake.

A number of studies have focused on particular aspects that may influence seismic performance of vertically irregular structures. De Stefano et al. (2005) investigated the sensitivity of vertically irregular $\mathrm{RC}$ framed structures to $\mathrm{P}-\Delta$ effects; in particular, a set of plane frames designed according to EC8 provisions for "high" ductility structures was considered. Comparison between fragility curves evaluated with and without $\mathrm{P}-\Delta$ effects revealed a remarkable influence of such effects in defining structural performance and, consequently, the safety levels associated with the assumed limit states.

Romão et al. (2004) studied the influence on the behavior of RC framed structures of two factors: (i) the variations in the axial force in the columns and (ii) different contributions of the floor slab to the flexural strength of beams. Three 6-storey plan frame structures with different degrees of irregularity were compared to their regular counterparts. When the axial force variations were considered, results showed an increase in lateral deformability, while no overall trend could be found on ductility demands and damage. Regarding the contribution of the floor slab, it was found that it varies considerably from structure to structure and also according to the ground motion intensity.

Several other papers have dealt with verification of the effectiveness of some simplified procedures, which, as they account for the higher modes of vibrations, appear promising in predicting behaviour of vertically irregular structures.

Chintanapakdee and Chopra (2004) investigated the accuracy in predicting seismic demands for vertically irregular frames through the modal pushover analysis (MPA) proposed in Chopra and Goel (2002), which includes the higher mode contributions. They considered many 12-storey irregular frames, with strong-columns and weak-beams, designed with three types of irregularity (of stiffness, strength, and their combinations) located differently along the height. Comparison with results from nonlinear dynamic analysis showed that the accuracy of MPA in determining storey drift ratio values did not deteriorate, in spite of irregularity provided in the middle or upper storeys, or in the presence of a soft and/or weak first storey. Conversely, the MPA procedure became less accurate for frames with stiff and strong first storeys, and when the irregularity is in the lower half of the height. Nevertheless, even for these cases, modal pushover analysis was capable of identifying the storeys with the largest drift demands, i.e. detect critical storeys in such frames.

Lignos and Gantes (2005) also investigated the effectiveness of MPA, with reference to various 4-storey and 9-storey steel braced frames with stiffness irregularities. Their study, however, led to the conclusion that for taller structures the modal pushover analysis, though capable of capturing the shape of mechanism, cannot predict collapse. Hence, it should not be used for investigation near collapse. 
As an alternative to the modal pushover analysis, Alba et al. (2005) proposed an extension of the N2 method, modified to consider the contribution of higher modes of vibration; with the proposed method, the capacity curve is actually obtained by means of a series of modal spectral analyses. Some case studies suggested to the authors that the method achieves more accuracy than the $\mathrm{N} 2$ procedure for structures with a significant contribution of the higher modes, independent of their vertically regular or irregular status.

The aim of Pinho and Antoniou (2005) was to verify the suitability of the Displacementbased Adaptive Pushover procedure (DAP), proposed in a previous work by the same authors in order to overcome limitations identified in the more traditional Force-based Adaptive Pushover methods (Antoniou and Pinho 2004). To this end, the DAP procedure was applied to a 4-storey building (tested at the JRC) characterized by relevant stiffness/strength variations at the third storey level, and yielded more accurate results in terms of deformation profiles and capacity curves.

The work of Bosco et al. (2002) was related to more traditional simplified design procedures. Starting with the premise that real multi-storey asymmetric structures rarely fulfil the strict conditions that characterize the so-called regularly asymmetric systems, they tried to define clear limits for application of simplified methods of analysis, developed rigorously only for such type of buildings. To this purpose, the authors proposed two parameters (Ghersi et al. 2002) that numerically define the vertical irregularity and showed how they are related to the ability of simplified methods to predict the elastic behavior of irregular structures. Moreover, the static analysis procedure seems to cover a wider field of application than the planar modal analysis corrected by torsional response of an equivalent single-storey system, as proposed by Chopra.

For what concerns experimental research, there are only very few studies on vertically irregular buildings, as already noted for plan-asymmetric building structures. An in-depth experimental study was conducted by Reinhorn etal. (2005) on a 3-storey three-bay steel structure, in which irregularity in elevation was due to the presence of two unequal towers. The selected model had independent vertical and lateral load resisting systems, the latter one consisting of planar moment frames with slotted connections to the floor slab, and designed according to the FEMA 273/274 equivalent static lateral force procedure. Shaking table tests were conducted by applying, with increasing amplitude, one historically recorded accelerogram, selected from a set of the Los Angeles area to be the most damaging for the tested structure. The experiment revealed structural damage (both local and global), which was carefully monitored and interpreted. Results were also used to validate several numerical techniques for predicting the seismic response of such structures near collapse. In addition, based on their experimental findings, the authors developed a refined numerical model for semi-rigid connections implemented into the IDARC2D computer program, which showed satisfactory results.

Lee and Ko (2004) used shaking table tests to assess the seismic responses of three 17-storey scaled RC bearing-wall structures, designed according to the Korean codes, with three types of irregularity at the bottom storeys: one had only a moment-resisting frame system, while the others had infilled shear walls in the central frame and in one of the exterior frames, respectively. Results showed that, due to the shear wall, lateral deformation at the lower floors of the frame is reduced considerably, but no significant effects were found on the reduction of the overturning deformation, base shear and overturning moment. Moreover, the authors concluded that hysteretic curve and the strength domain, in terms of base shear and torque, clearly reveal the most probable mode of vibration leading to failure. 


\section{Conclusions}

This paper reports on research developments on the seismic behavior of both plan and vertically irregular building structures since 2002.

Because of the complex behavior of such structures under earthquake excitations, it is not surprising that, in spite of the large research efforts in plan irregular building structures dating back to the 1970s, even in recent years, many papers have been devoted to a better understanding of seismic response-especially in the inelastic range-mainly of simplified one-storey building models. Namely, although results are affected by large dispersions arising in the nonlinear range of behavior, significant conclusions have been drawn regarding magnitude of rotational response, bi-directional eccentricity and input ground motion, and optimized strength distributions.

Many studies adopting more realistic multi-storey models have evidenced the shortcomings of simplified one-storey models, especially in predicting qualitative features of inelastic response, such as location of the most stressed resisting elements. A number of assessments of code-designed plan irregular structures have also shown that specifications subscribed by current major seismic codes are in need of re-examination in order to properly deal with nonlinear behaviour. More recently, large research efforts have been devoted to developing pushover procedures for plan irregular systems, reaching effective solutions.

As an alternative to traditional design solutions, fresh ideas are coming from studies on the use of passive control by means of various innovative technologies aimed at mitigating the effects of building torsional response. In particular, in addition to base isolation, various types of devices, viscous and frictional, have been considered through ever more refined modeling, and different optimization techniques have proved effective in identifying the amount and location of such devices needed to achieve significant reductions in torsional response.

Less research has been devoted to vertically irregular building structures than planasymmetric ones. Nevertheless, in recent years, research interest in the field of building structures with vertical irregularity has grown, thanks in part to the ever greater availability of efficient nonlinear computer codes that enable dynamic analysis of large multi-storey buildings.

Recent activities on vertically irregular structures have clarified that discontinuities of mass, stiffness or strength along the height, considered by current seismic codes as irregularities in elevation, do not necessarily result in actual increases in plastic demands and, more generally, in poor seismic behaviour. Thus, criteria in major international codes aimed at identifying vertical irregularities seem to penalize such discontinuities excessively and that codes are in need of improvement in order to define indicators that actually predict irregular behaviour. On the other hand, despite some exceptions, design rules specified by major seismic codes for vertically irregular buildings have resulted in satisfactory seismic performances. Lastly, some papers have been dealing with modification of nonlinear pushover procedures for vertically irregular buildings, achieving good correlation of results with those from nonlinear dynamic analysis.

In conclusion, research activity on seismic response of irregular buildings is still very lively, as revealed by the impressive number of papers published in the period 2002-2006, and full clarification of the main issues, both behavioral and design oriented, is on the way to be achieved, as shown in this paper. 


\section{References}

Alba F, Ayala AG, Bento R (2005) Seismic performance evaluation of plane frames regular and irregular in elevation. In: Proceedings of the 4th European workshop on the seismic behaviour of irregular and complex structures, CD ROM. Thessaloniki, August 2005

Almazan JL, De la Llera JC (2003) Accidental torsion due to overturning in nominally symmetric structure isolated with FPS. Earthq Eng Struct Dyn 32:919-948

Antoniou S, Pinho R (2004) Development and verification of a displacement-based adaptive pushover procedure. J Earthquake Eng 8(5):643-661

Athanassiadou C, Bervanakis S (2005) Seismic behaviour of R/C buildings with setbacks designed to EC8. In: Proceedings of the 4th European workshop on the seismic behaviour of irregular and complex structures, CD ROM. Thessaloniki, August 2005

Ayala AG, Perez R (2005) Performance based seismic design of asymmetric buildings. In: Proceedings of the 4th European workshop on the seismic behaviour of irregular and complex structures, CD ROM. Thessaloniki, August 2005

Aziminejad A, Moghadam AS (2005) Performance of asymmetric single story buildings based on different configuration of center of mass, rigidity and resistance. In: Proceedings of the 4th European workshop on the seismic behaviour of irregular and complex structures, CD ROM. Thessaloniki, August 2005

Bosco M, Ghersi A, Marino E, Rossi PP (2002) Effects of in elevation irregularity on the elastic seismic response of in-plan asymmetric buildings. In: Proceedings of the third European workshop on the seismic behaviour of irregular and complex structures, CD ROM. Florence, September 2002

Castillo R, Paulay T, Carr AG (2002) Design concepts for ductile single mass asymmetric systems. In: Proceedings of the third European workshop on the seismic behaviour of irregular and complex structures, CD ROM. Florence, September 2002

Chintanapakdee C, Chopra AK (2004) Evaluation of modal pushover analysis using vertically irregular frames. In: Proceedings of the 13th World conference on earthquake engineering, CD ROM. Vancouver, August 2004

Chopra AK, Goel GK (2002) A modal push over analysis procedure for estimating seismic demands for buildings. Earthq Eng Struct Dyn 31:561-582

Chopra AK, Goel GK (2004) A modal push over analysis procedure to estimate seismic demands for unsymmetric-plan buildings. Earthq Eng Struct Dyn 33:903-927

Das S, Nau M (2003) Seismic design aspects of vertically irregular reinforced concrete buildings. Earthq Spectra 19:455-477

De-la-Colina J (2003) Assessment of design recommendations for torsionally unbalanced multistorey buildings. Earthq Spectra 19:47-66

De la Llera JC, Almazan JL (2003) An experimental study of nominally symmetric and asymmetric structures isolate with the FPS. Earthq Eng Struct Dyn 32:891-918

De la Llera JC, Almazan JL, Vial IJ (2005) Torsional balance of plan asymmetric structures with frictional dampers: analytical results. Earthq Eng Struct Dyn 34:1089-1108

De Stefano M, Pintucchi B (2002) A model for analyzing inelastic seismic response of plan-irregular building structures. In: Proceedings of the 15th ASCE engineering mechanics conference, CD ROM. New York, June 2002

De Stefano M, Marino EM, Viti S (2005) Evaluation of second order effects on the seismic response of vertically irregular RC framed structures. In: Proceedings of the 4th European workshop on the seismic behaviour of irregular and complex structures, CD ROM. Thessaloniki, August 2005

De Stefano M, Marino EM, Rossi PP (2006) Effect of overstrength on the seismic behaviour of multi-storey regularly asymmetric buildings. Bull Earthquake Eng 4(1):23-42

Duan XN, Chandler AM (1995) Seismic torsional response and design procedures for a class of setback frame buildings. Earthq Eng Struct Dyn 24:761-777

Dutta SC, Das PK (2002a) Inelastic seismic response of code-designed reinforced concrete asymmetric buildings with strength degradation. Eng Struct 24:1295-1314

Dutta SC, Das PK (2002b) Validity and applicability of two simple hysteresis models to assess progressive seismic damage in R/C asymmetric buildings. J Sound Vibrat 257:753-777

Fajfar P, Magliulo G, Marušić D, Peruš I (2002) Simplified non-linear analysis of asymmetric buildings. In: Proceedings of the third European workshop on the seismic behaviour of irregular and complex structures, CD ROM. Florence, September 2002

Fajfar P, Marušić D, Perus I (2005) The extension of the N2 method to asymmetric buildings. In: Proceedings of the 4th European workshop on the seismic behaviour of irregular and complex structures, CD ROM. Thessaloniki, August 2002 
Fernandez Davila VI, Cruz EF (2006) Parametric study of the non-linear seismic response of three-dimensional building models. Eng Struct 28:756-770

Fragiadakis M, Vamvatsikos D, Papadrakakis M (2005) Evaluation of the influence of vertical stiffness irregularities on the seismic response of a 9-story steel frame. In: Proceedings of the 4th European workshop on the seismic behaviour of irregular and complex structures, CD ROM. Thessaloniki, August 2005

Ghersi A, Marino E, Rossi PP (2002) Analytical and numerical determination of the exact location of the optimum torsion axis. In: Proceedings of the third European workshop on the seismic behaviour of irregular and complex structures, CD ROM. Florence, September 2002

Ghobarah A, Aziz TS, Mohammed HH (2005) Response of mass eccentric torsionally coupled primarysecondary system. In: Proceedings of the 4th European workshop on the seismic behaviour of irregular and complex structures, CD ROM. Thessaloniki, August 2005

Goel RK (1998) Effects of supplemental viscous damping on seismic response of asymmetric-plan systems. Earthq Eng Struct Dyn 27:125-141

Goel RK (2000) Seismic behaviour of asymmetric buildings with supplemental damping. Earthq Eng Struct Dyn 29:461-480

Goel RK, Booker CA (2001) Effects of supplemental viscous damping on inelastic seismic response of asymmetric systems. Earthq Eng Struct Dyn 30:411-430

Heredia-Zavoni E, Machicao-Barrionuevo R (2004) Response to orthogonal components of ground motion and assessment of percentage combination rules. Earthq Eng Struct Dyn 33:271-284

Kappos AJ, Scott SG (1998) Seismic assessment of an R/C building with setbacks using nonlinear static and dynamic analysis procedures. In: Booth ED(ed) Seismic design practice into the next century. Balkema, Rotterdam

Khoury W, Rutenberg A, Levy R (2005) On the seismic response of asymmetric setback perimeter-frame structures. In: Proceedings of the 4th European workshop on the seismic behaviour of irregular and complex structures, CD ROM. Thessaloniki, August 2005

Kilar V, Fajfar P (1997) Simple push-over analysis of asymmetric buildings. Earthq Eng Struct Dyn 26:233249

Kilar V, Fajfar P (2002) Seismic analysis of eccentric R/C buildings by the N2 methods. In: Proceedings of the third European workshop on the seismic behaviour of irregular and complex structures, CD ROM. Florence, September 2002

Kim J, Bang S (2002) Optimum distribution of added viscoelastic dampers for mitigation of torsional response of plan-wise asymmetric structures. Eng Struct 24:1257-1269

Lee H-S, Ko D-W (2004) Seismic response of high-rise RC bearing-wall structures with irregularities at bottom stories. In: Proceedings of the 13th World conference on earthquake engineering, CD ROM. Vancouver, August 2004

Lee S, Son D, Kim J, Min KW (2004) Optimal design of viscoelastic dampers using eigenvalue assignment. Earthq Eng Struct Dyn 33:521-542

Lignos DG, Gantes CJ (2005) Seismic demands for steel braced frames with stiffness irregularities based on modal pushover analysis. In: Proceedings of the 4th European workshop on the seismic behaviour of irregular and complex structures, CD ROM. Thessaloniki, August 2005

Lin WH, Chopra AK (2001) Understanding and predicting effects of supplemental viscous damping on seismic response of asymmetric one-storey systems. Earthq Eng Struct Dyn 30:1475-1494

Lin WH, Chopra AK (2003a) Asymmetric one-storey with non linear viscous and viscoelastic dampers: earthquake response. Earthq Eng Struct Dyn 32:555-577

Lin WH, Chopra AK (2003b) Asymmetric one-storey with non linear viscous and viscoelastic dampers: simplified analysis and supplemental damping design. Earthq Eng Struct Dyn 32:579-596

Magliulo G, Ramasco R, Realfonzo R (2002) A critical review of seismic code provisions for vertically irregular frames. In: Proceedings of the third European workshop on the seismic behaviour of irregular and complex structures, CD ROM. Florence, September 2002

Marušic D, Fajfar P (2005) On the inelastic seismic response of asymmetric buildings under bi-axial excitation. Earthq Eng Struct Dyn 34:943-963

Myslimaj B, Tso WK (2005) A design-oriented approach to strength distribution in single story asymmetric systems with elements having strength-dependent stiffness. Earthq Spectra 21:197-212

Moghadam AS, Tso WK (2000) Pushover analysis for asymmetric and set-back multi-story buildings. In: Proceedings of the 12th World conference on earthquake engineering, CD ROM. Auckland, New Zealand, February 2000

Murnal P, Sinha R (2004) Behaviour of torsionally coupled structures with variable frequency pendulum isolator. J Struct Eng 130(7):1041-1054

Negro P, Mola E, Gutierrez E (2005) Application of the Karhunen-Loewe method to the analysis of the results of a PSD test on a torsionally unbalanced three-storey R/C building. In: Proceedings of the 4th European 
workshop on the seismic behaviour of irregular and complex structures, CD ROM. Thessaloniki, August 2005

Paulay T (2002) An estimation of displacement limits for ductile systems. Earthq Eng Struct Dyn 31:583-599

Penelis GrG, Kappos AJ (2005) Inelastic torsion effects in 3D pushover analysis of buildings. In: Proceedings of the 4th European workshop on the seismic behaviour of irregular and complex structures, CD ROM. Thessaloniki, August 2005

Peruš I, Fajfar P (2002) On inelastic seismic response of asymmetric single-storey structures under bi-axial excitation. In: Proceedings of the third European workshop on the seismic behaviour of irregular and complex structures, CD ROM. Florence, September 2002

Peruš I, Fajfar P (2005) On the inelastic torsional response of single-storey structures under bi-axial excitation. Earthq Eng Struct Dyn 34:931-941

Pettinga D, Pampanin S, Christopoulos C, Priestley MJN (2005) Effects of irregularities on the residual displacements of structures subjected to inelastic torsional response. In: Proceedings of the 4th European workshop on the seismic behaviour of irregular and complex structures, CD ROM. Thessaloniki, August 2005

Pinho R, Antoniou S (2005) A displacement-based adaptive pushover algorithm for assessment of vertically irregular frames. In: Proceedings of the 4th European workshop on the seismic behaviour of irregular and complex structures, CD ROM. Thessaloniki, August 2005

Pintucchi B, De Stefano M, Gasparini G, Silvestri S, Trombetti T (2005) Numerical verification of the effectiveness of the "alpha method" for the estimation of the maximum rotational response of eccentric systems. In Proceedings of the 4th European workshop on the seismic behaviour of irregular and complex structures, CD ROM. Thessaloniki, August 2005

Reinhorn AM, Kusumastuti D, Rutenberg A (2005) Seismic response of irregular frame structures near collapse: experimental and analytical investigation. In: Proceedings of the 4th European workshop on the seismic behaviour of irregular and complex structures, CD ROM. Thessaloniki, August 2005

Romão X, Costa A, Delgado R (2004) Seismic behaviour of reinforced concrete frames with setbacks. In: Proceedings of the 13th World conference on earthquake engineering, CD ROM. Vancouver, August 2004

Rutenberg A (2002) EAEE Task Group (TG) 8: behaviour and irregular and complex structures-progress since 1998. In: Proceedings of the 12th European conference on earthquake engineering, CD ROM. London, September 2002

Ryan KL, Chopra AK (2004) Estimation of seismic demands on isolators in asymmetric buildings using non-linear analysis. Earthq Eng Struct Dyn 33:395-418

Shakib H, Fuladgar A (2003) Effect of vertical component of earthquake on the response of pure-friction base-isolated asymmetric buildings. Eng Struct 25:1841-1850

Singh MP, Singh S, Moreschi LM (2002) Tuned mass dampers for response control of torsional buildings. Earthq Eng Struct Dyn 31:749-769

Stathopoulos KG, Anagnostopoulos SA (2002) Inelastic earthquake induced torsion in buildings: results and conclusions from realistic models. In: Proceedings of the 12th European conference on earthquake engineering, CD ROM. London, September 2002

Stathopoulos KG, Anagnostopoulos SA (2003) Inelastic earthquake response of single-story asymmetric buildings: an assessment of simplified shear-beam models. Earthq Eng Struct Dyn 32:1813-1831

Stathopoulos KG, Anagnostopoulos SA (2005) Inelastic torsion of multi-storey buildings under earthquake excitations. Earthq Eng Struct Dyn 34:1449-1465

Sommer A, Bachmann H (2005) Seismic behaviour of asymmetric RC wall buildings: principles and new deformation-based design methods. Earthq Eng Struct Dyn 34:101-124

Tena-Colunga A (2004) Evaluation of the seismic response of slender, setback RC moment-resisting frame buildings designed according to the seismic guidelines of a modern building code. In: Proceedings of the 13th World conference on earthquake engineering, CD ROM. Vancouver, August 2004

Tena-Colunga A, Gomez-Soberon L (2002) Torsional response of base-isolated structures due to the asymmetries in the superstructure. Eng Struct 24:1587-1599

Tena-Colunga A, Zambrana-Rojas C (2006) Dynamic torsional amplifications of base-isolated structures with an eccentric isolation system. Eng Struct 28:72-83

Tremblay R, Poncet L (2005) Seismic performance of concentrically braced steel frames in multistory buildings with mass irregularity. J Struct Eng 131:1363-1375

Trombetti TL, Conte JP (2005) New insight into a simplified approach to seismic analysis of torsionally coupled one-story, elastic systems. J Sound Vibrat 286:265-312

Tso WK, Moghadam AS (1997) Seismic response of asymmetrical buildings using push-over analysis. In: Proceedings of workshop on seismic design methodologies for the next generation of codes. Balkema, Rotterdam 
Tso WK, Myslimaj B (2002) Effect of strength distribution on the inelastic torsional response of asymmetric structural systems. In: Proceedings of the 12th European conference on earthquake engineering, CD ROM. London, September 2002

Tso WK, Myslimaj B (2003) A yield displacement distribution-based approach for strength assignment to lateral force-resisting elements having strength dependent stiffness. Earthq Eng Struct Dyn 32:23192351

Wang J, Lin C (2005) Seismic performances of multiple tuned mass dampers for soil-irregular building interaction systems. Int J Solids Struct 42:5536-5554

Yoshida O, Dyke SJ, Giacosa LM, Truman KZ (2003) Experimental verification on torsional response control of asymmetric buildings using MR dampers. Earthq Eng Struct Dyn 32:2085-2105 